\title{
Study of fault plane solutions and stress drop using local broadband network data: the 2011 Sikkim Himalaya earthquake of Mw 6.9 and its aftershocks
}

\author{
Santanu Baruah ${ }^{1,2,}{ }^{*}$, Sebastiano D’Amico ${ }^{3}$, Sowrav Saikia ${ }^{4}$, J. L. Gautam ${ }^{4}$, R. K. Mrinalinee Devi ${ }^{1}$, \\ Goutam Kashyap Boruah ${ }^{1}$, Antara Sharma ${ }^{1,2}$, Mohamed F Abdelwahed ${ }^{5,6}$ \\ ${ }^{1}$ Geosciences \& Technology Division, CSIR-North East Institute of Science \& Technology (NEIST), India \\ 2. Academy of Scientific and Innovative Research (AcSIR), CSIR-NEIST Campus, India \\ 3. Dept. of Geosciences, University of Malta, Malta \\ 4. National Center for Seismology, Ministry of Earth Sciences, New-Delhi, India \\ 5. Geohazards Research Center, King Abdulaziz University, Jeddah, Saudi Arabia \\ 6. National Research Institute of Astronomy and Geophysics, Cairo, Egypt
}

Article history

Received January 27, 2017; accepted January 22, 2018.

Subject classification:

Sikkim Himalaya; Stress Drop; Seismic moment.

\begin{abstract}
Fault plane solutions of the September 18, 2011 Sikkim Himalaya earthquake of $M w 6.9$ and its four aftershocks (Mw>4.0) are studied by waveform inversion using the local broadband network data. The solutions show pure strike-slip mechanisms; one aftershock show thrust faulting with strike-slip component. Strike-slip mechanisms indicate predominant transverse tectonics in Sikkim, in the eastern Himalaya region, unlike predominant thrust tectonics in the western Himalaya. The 2011 main shock occurred at a much deeper depth ( 47 km) compared to the shallower $(<20 \mathrm{~km})$ thrust events in the western Himalaya. Further, analysis of ground acceleration spectra reveals low stress drop (14-38 bars) in agreement with the relatively long source duration and small co-seismic slip of the main shock as well as the aftershocks. We interpret the low stress drop in terms of lower energy release due to reactivation of the NNW-SSE trending Tista fault in contrast to that of the Himalayan thrust tectonics. The low stress drop also indicates a pre-existing brittle zone or fault zone at deeper depth or mantle depth.
\end{abstract}

\section{Introduction}

A powerful destructive earthquake of $\mathrm{Mw} 6.9$ at a depth of $\sim 47 \mathrm{~km}$ (GCMT report), struck on September 18, 2011 in north-west Sikkim, at the border between India and Nepal (Figure 1). The earthquake was widely felt in Sikkim, Assam, Meghalaya, northern parts of West Bengal, Bihar and parts of other eastern and northern regions of India. The earthquake caused severe damages to property and also caused 60 casualties. This is the strongest instrumentally recorded earthquake in the Sikkim Himalaya during the last two centuries [Pradhan et al. 2013]. The most significant signatures of the 2011 Sikkim earthquake are landslides and landslide-induced loss of life as well as damage to the economy and infrastructure due to which the maximum intensity is reached to VII (MM scale) [Mahajan et al. 2012, Sharma et al. 2013] Poor construction of the houses and the hilly landslide-prone terrain are believed to be the main cause of such extensive damage [e.g., INTACH 2012, Rai et al. 2012]. Al-together there were 292 aftershocks (Mw>1.0) reported by a local broadband close-spaced microearthquake network of the National Geophysical Research Institute (NGRI) [Ravi et al. 2012], but the national network of the India Meteorological Department (IMD) as well as the global network (USGS, NEIC) reported only four aftershocks $\mathrm{Mw} \geq 4.0$ (Figure 1). The IMD reported that the main shock was preceded by a foreshock of Mw 4.9 at $26 \mathrm{~km}$ depth, on June 3, 2011 (Figure 1).

The devastating $2011 \mathrm{Mw} 6.9$ Sikkim earthquake highlighted the urgent need to reassess the seismotectonic of the region. Using past global seismological data, GPS data, and the fault plane solutions of the 2011 Sikkim earthquake, several authors have tried to review 


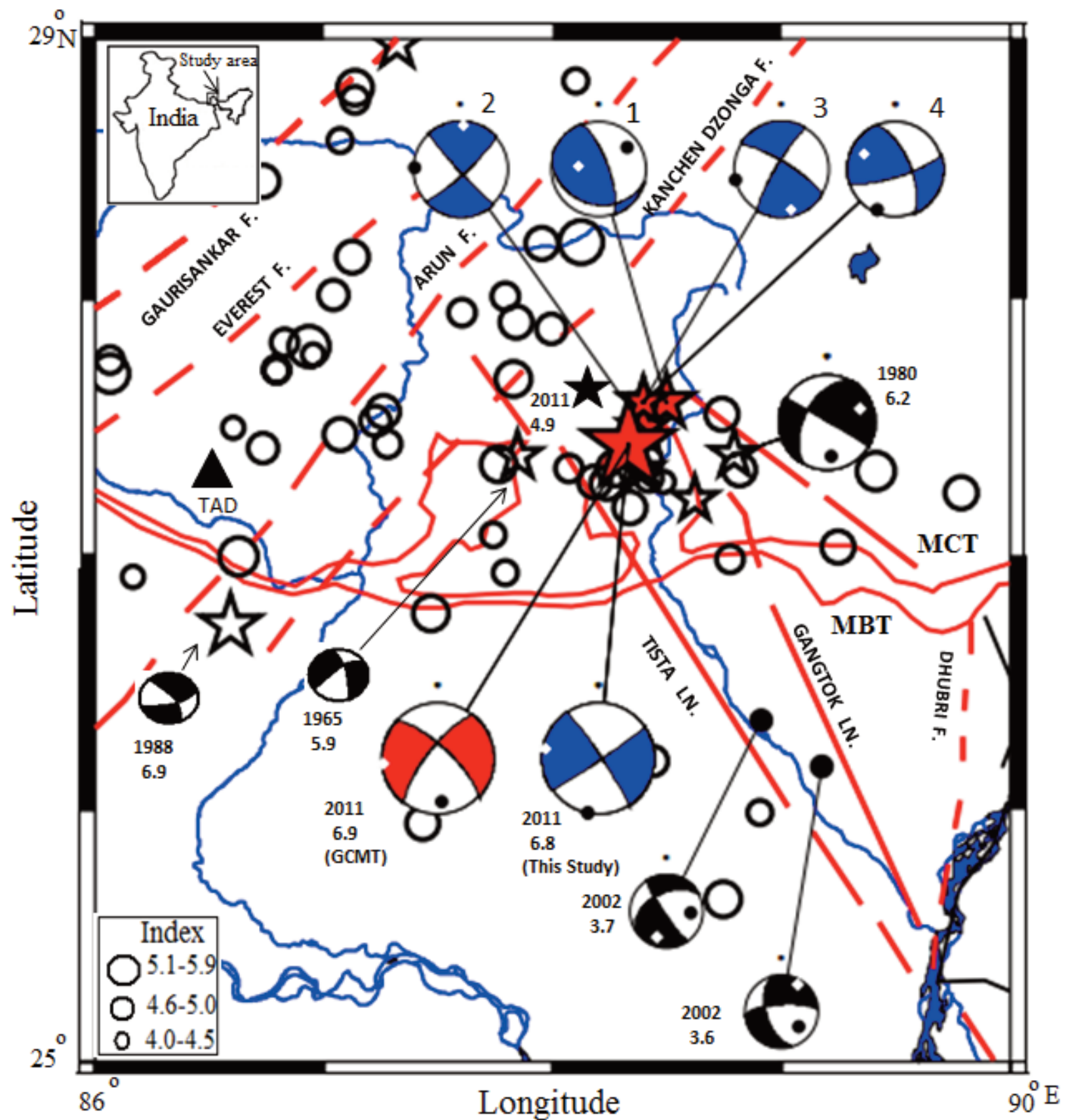

Figure 1. Tectonic map of the Sikkim Himalaya [after De and Kayal 2003] showing the epicentres of EHB relocated earthquakes (1965-2007). The 18 September 2011 main shock and four significant aftershocks $(M \geq 4.0)$ are shown by red stars. The foreshock of the earthquake is shown by filled black star. The open black stars show the two damaging strong earthquakes $(\mathrm{M} \geq 5.9)$ with CMT fault-plane solutions. The solution of the 1988 earthquake is from Banghar (1991)based on first motion plot, and the waveform inversion solutions of two smaller events of 2002 are from Baruah et al. [2012a,b]. MCT: Main Central Thrust, MBT: Main Boundary Thrust, HFT: Himalayan Frontal Thrust, and GL: Goalpara lineament. The blue line indicates the river system. The red beach ball indicates the GCMT solution while blue beach ball indicates the solutions obtained in this study. The fault plane solutions of the four aftershocks (named as 1, 2, 3, 4) are also shown as blue beach ball.

the seismotectonics of the Sikkim Himalaya [e.g. Rajendran et al. 2011, Kayal et al. 2011, Thakur et al. 2012, Dasgupta et al. 2013, Chopra et al. 2013, Pradhan et al. 2013, Paul et al. 2015, Baruah et al. 2014 and Mukul et al. 2014]. The transverse tectonics on the steeply dipping near vertical mantle reaching Tista fault zone was suggested to generate the main shock. Finite fault model analysis indicates that the surface level Peak
Ground Acceleration (PGA) values near to source region might reach more than $0.3 \mathrm{~g}$ [Raghukanth et al. 2012]. Ravi Kumar et al. [2012] made a detailed study of the aftershocks recorded by the NGRI local network, and concluded that the near vertical mantle reaching Tista fault caused the main shock and aftershocks. A rupture model using simulation of near-field and farfield accelerograms was presented by Joshi et al. [2012]. 
Chopra et al [2013] determined source parameters of the main shock by strong ground motion modelling in terms of PGA.

In this study, we have determined fault plane solutions of the 2011 main shock and its four small aftershocks (Mw 3.9-4.5) by waveform inversion using the local broadband data of the IMD national network. Although the main shock GCMT was immediately reported, but fault plane solutions of the four small aftershocks were not reported earlier. We have critically examined these fault plane solutions of the main shock and the four selected aftershocks using the IMD permanent broadband network data, and we have also estimated the source parameters of these events by spectral analysis. These results, with their tectonic implications are presented here.

\section{Tectonic setting}

The formation of the Himalaya resulted due to the continent-continent collision of Indian plate with Eurasian plate at $\sim 50 \mathrm{Ma}$ [e.g. Allegre et al. 1984, Baccheschi and D'Amico 2014 and reference therein]. In the Sikkim Himalaya, the major tectonic features are the Main Boundary Thrust (MBT) and the Main Central Thrust (MCT) parallel to the Himalayan trend, and the NNW-SSE trending Tista and Gangtok lineaments, the WNW-ESE trending Goalpara lineament and the SW-NE trending Kanchanjangha lineament transverse to the Himalayan trend [GSI 2000]. The MCT in the Sikkim Himalaya has taken a curvilinear loop shape indicating thicker sediments (Figure 1). A conceptual tectonic model of the Himalaya was first suggested by Seeber et al. [1981] based on the known geology, geophysics and teleseismic hypocentral data. In this model, the two active thrusts, the MBT and MCT, are contemporaneous in nature. However, Ni and Barazangi [1984] has suggested that the MCT is dormant while the MBT is active. The interface between the subducting Indian slab and the Himalayan sedimentary wedge is named the "Plane of Detachment" in the proposed model [Seeber et al. 1981]. Further north, below the MCT lies the "ramp", referred to as "Basement Thrust Front" (also known as Basal Detachement/Decollement or Main Himalayan Thrust), that accumulates the tectonic stress due to northward movement of the Indian plate; abrupt release is believed to be the main cause of earthquakes on the plane of detachment at a shallower depth $(0-20 \mathrm{~km})$.

Based on local temporary network data, Kayal [2001 and 2010] argued that the Himalayan shallow thrust faulting earthquakes in the western Himalaya fits fairly well with the most accepted conceptual tectonic model, but the deeper $(30-60 \mathrm{~km})$ strike-slip faulting earthquakes in the eastern Himalaya cannot be explained as plane of detachment earthquakes. The focal depth of the recent well-recorded 1988 strong earthquake (Mw 6.9) at the Bihar-Nepal border foothills region was given at 50-60 km by different agencies such as USGS, ISC and ERI. Furthermore, Monsalve et al. [2006] reported deeper $(30-60 \mathrm{~km})$ source zones of earthquakes in the foothills region; these results were based on permanent digital network data of Nepal, central Himalaya. After the 1988 strong foothills earthquake in the region, the eastern Himalaya produced the 2011 strong Sikkim earthquake (Mw 6.9) further north at the surface trace of the MCT (Figure 1). The 1988 event as well as the 2011 strong earthquakes in this region, have given us the opportunity to understand the earthquake processes better in the eastern Himalaya region. Unlike the 1988 foothills earthquake, the 2011 Sikkim Himalaya earthquake provided local broadband network data that may shed new light to our understanding of the eastern Himalaya earthquakes at the Himalaya Seismic Belt (HSB) zone.

\section{Data Analysis}

\subsection{Hypocenter Locations}

In this study, the earthquake data recorded by the broadband seismic network of IMD in the North-east India region are used for analysis. Each station is equipped with tri-axial REFTEK 151B Broadband velocimeters with a sampling rate of $100 \mathrm{~Hz}$. Several locations have been reported for the main shock of the 2011 Sikkim earthquake by different national and international agencies (Table 1). The reported source depth was the most uncertain parameter, ranging from $10 \mathrm{~km}$ to $50 \mathrm{~km}$. We have reanalysed the hypocentral parameters using nine local broadband station data of the IMD. We used the HYPOCENTER programme of Lineart et al. [1986] and a velocity model proposed by Acton et al. [2011] for the region. The estimated location errors are $\pm 2.1 \mathrm{~km}$ and \pm 5.1 along the horizontal and depth respectively, and the root mean square error $1.3 \mathrm{sec}$. The same programme is also used for locations of the aftershocks.

\subsection{Spectral Analysis}

Source parameters are studied by spectral analysis. For spectral analysis, first we applied a base-line correction and a cosine taper to the vertical component of the P-wave seismograms. We then transformed the seismograms from velocity to displacement. We selected a time window of several seconds beginning just 
BARUAH ET AL.

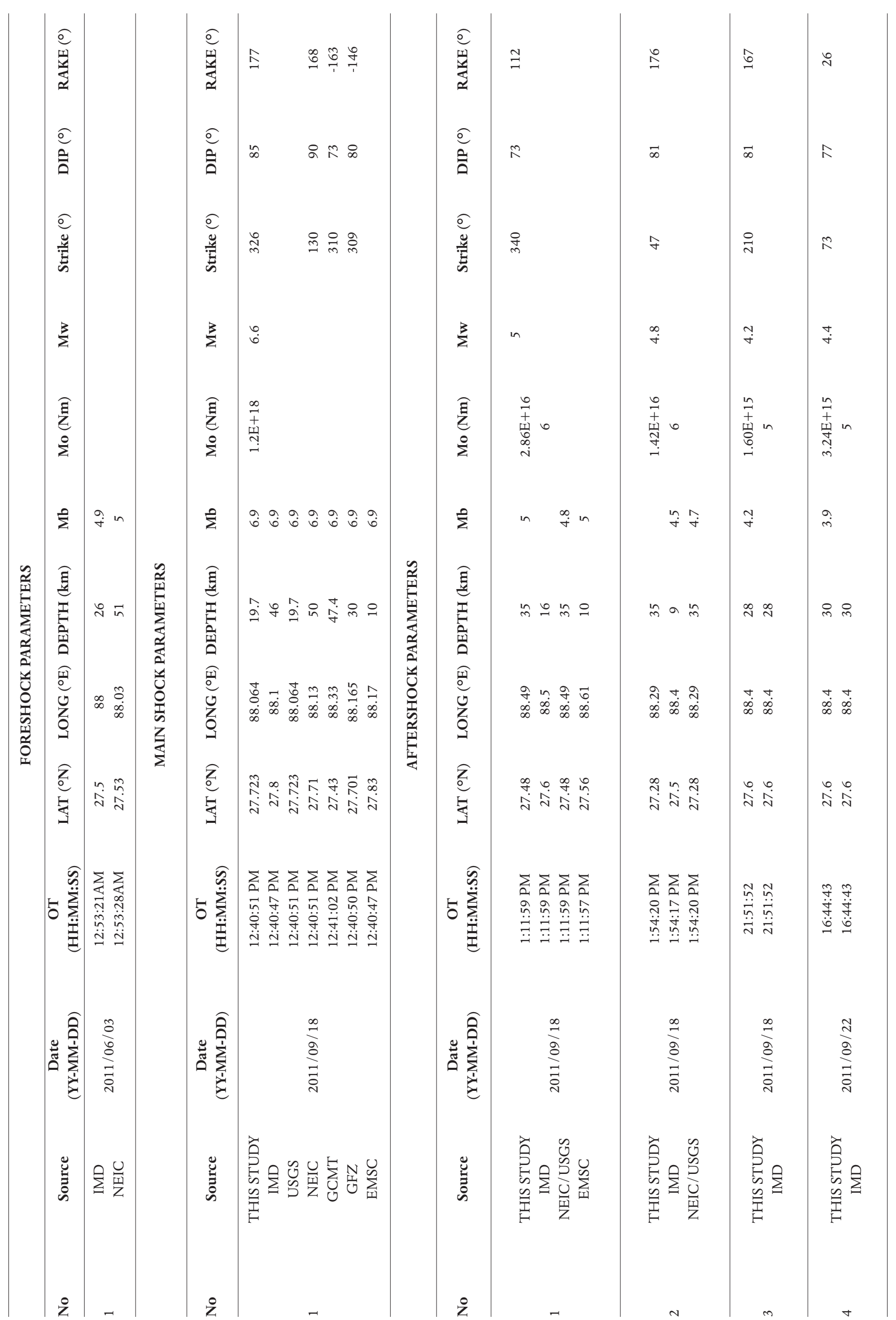

Table 1. Hypocentral and Focal parameters of $18^{\text {th }}$ September, 2011 Sikkim earthquake and its foreshock and aftershocks. 
before the first arrival, usually 5 sec before the onset of the first arrival, and calculated the amplitude spectrum using Fast Fourier Transformation (FFT). All spectra presented in this paper have been corrected for instrument response and for attenuation using the results of Thirunavukarasu et al. [2016] where $Q=100$. We characterised the spectra at a constant level $\mathrm{A}_{0}$ for the lower frequencies, and with a fall-off above the corner frequency $(f c)$. Earthquake source parameters are estimated following the Brune [1970] model as modified by Hanks and Wyss [1972].

In agreement with most used theoretical models of seismic sources, the far-field displacement $\Omega(f)$ can be described by a -corner frequency model:

$$
\Omega(f)=\frac{\Omega_{0}}{\left[1+\left(f / f_{C}\right)^{n}\right]^{1 / \gamma}}
$$

where, $\Omega_{0}$ is the low-frequency spectral level, $\mathrm{f}_{\mathrm{C}}$ is the corner frequency, $\mathrm{n}$ is the high-frequency spectral falloff, and $\gamma$ is a constant. If $\gamma=1$, Equation (1) is the spectral shape proposed by Brune [1970].

The average value of corner frequency $\left\langle f_{c}\right\rangle$ is expressed as follows:

$$
\left\langle f_{c}\right\rangle=\operatorname{anti} \log \left[\frac{1}{N} \sum_{i=1}^{N} \log f_{c_{i}}\right]
$$

where $f_{\mathcal{c}_{i}}$ is the corner frequency at the $\mathrm{i}^{\text {th }}$ station and $\mathrm{N}$ is the number of stations used in this study. The antilog defines the inverse of logarithm.

Source parameters (seismic moment, moment magnitude, stress drop, and source radius) are then calculated for the main shock and aftershocks. The seismic moment (Mo) is estimated from the low-frequency level $\left(\Omega_{0}\right)$ using the relation of Keilis-Borok [1959],

$$
M_{0}=4 \pi \rho V_{p}^{3} R \frac{\Omega_{0}}{R_{\theta \phi}}
$$

where, $\rho=2700 \mathrm{~kg} / \mathrm{m}^{3}$ is the density, $\mathrm{Vp}$ is the average Pwave velocity, $\mathrm{R}$ is the source to receiver distance, and $R_{\theta \phi}$ is the a co-efficient accounted for the combined correction for radiation pattern, free surface amplification and site effects. The root mean square average of radiation pattern co-efficient $R_{\theta \phi}=0.52$ is used for all the events [Boore and Boatwright 1984].

An average seismic moment $\left\langle M_{0}\right\rangle$ from all of the stations is determined from the average of the logarithmic values using the following relation [Archuleta et al. 1982]:

$$
\left\langle M_{0}\right\rangle=\operatorname{anti} \log \left[\frac{1}{N} \sum_{i=1}^{N} \log M_{0_{i}}\right]
$$

where, $\mathrm{N}$ is the number of stations used.

The average source radius $\langle R(P)\rangle$ is computed using the modified Brune [1970] formula for P-wave spectrum [Hanks and Wyss 1972]:

$$
\langle R(P)\rangle=\frac{2.34 V_{P}}{2 \pi\left\langle f_{C}(P)\right\rangle}
$$

Similarly, stress drop is estimated using the following equation:

$$
\langle\Delta \sigma\rangle=\frac{7\left\langle M_{0}\right\rangle}{16\langle R(P)\rangle^{3}}
$$

We calculated moment magnitude from seismic moment following the definition of Hanks and Kanamori [1979]:

$$
M_{w}=\frac{2}{3} \log M_{0}-10.73
$$

where $M_{0}$ is measured in dyne.cm.

For each seismic event, we determined A0 and fc and the corresponding source radius $\mathrm{r}$ and seismic moment $M_{0}$ for each seismic station with signal-to-noise ratio greater than 1 . The final $M_{0}$ and $\mathrm{R}$ are the average of these values. Stress drop, average displacement and moment magnitude are then calculated from these averaged $M_{0}$ and $\mathrm{R}$. The resulting source parameters for the investigated earthquakes are summarized in Table 2

\subsection{Focal Mechanisms and Stress Drop}

Focal mechanisms are obtained by the moment tensor inversions. We have used the Fortran-Matlab based ISOA-GUI package developed by Sokos and Zahradnik [2008] for moment tensor inversion. In this process, the complete velocity records are used without selecting any particular phases. The 3-component digital records are first converted into displacement waveforms. The displacement waveforms are then filtered between 0.01 and $9 \mathrm{~Hz}$ using four pole ban-pass Butterworth filters. The high frequency components are excluded because it is difficult to model high frequency components as it requires a precise knowledge of detailed sub-surface crustal velocity model. Subsequently resampling of records from a frequency of $100 \mathrm{~Hz}$ to $33 \mathrm{~Hz}$ is carried having with transfer function of the seismometer. Necessary DC removal and Trend line removal are performed. Green's functions are then computed in the complex spectral domain using the suitable crustal velocity model of Acton et al. [2011] pertinent to the region at a point source by Discrete Wavenumber (DW) method [Bouchan 1981]. The Green's functions are then convolved with appropriate instrument response and 
BARUAH ET AL.

\begin{tabular}{|c|c|c|c|c|c|c|c|c|c|}
\hline STATION & LAT $\left({ }^{\circ} \mathbf{N}\right)$ & LONG $\left({ }^{\circ} \mathrm{E}\right)$ & $\begin{array}{l}\text { ELEVATION } \\
\text { (meter) }\end{array}$ & $\begin{array}{l}\text { Epicentral } \\
\text { distance } \\
(\mathbf{k m})\end{array}$ & Mw & $\begin{array}{c}\text { Mo } \\
\text { (dyne.sec) }\end{array}$ & $f c$ & $\begin{array}{c}\text { STRESS } \\
\text { DROP } \\
\text { (bars) }\end{array}$ & $\begin{array}{l}\text { SOURCE } \\
\text { RADIUS } \\
(\mathrm{km})\end{array}$ \\
\hline $\begin{array}{l}\text { Dhubri } \\
\text { (DHU) }\end{array}$ & 26.02 & 89.99 & 205 & 219.38 & 5.66 & $3.84 \mathrm{E}+24$ & 0.18 & 20.06 & 10.45 \\
\hline $\begin{array}{l}\text { Dibrugarh } \\
\text { (DIB) }\end{array}$ & 27.467 & 94.911 & 90 & 634.34 & 6.19 & $2.44 \mathrm{E}+25$ & 0.11 & 22.89 & 12.19 \\
\hline $\begin{array}{l}\text { Guwahati } \\
\text { (GAU) }\end{array}$ & 26.193 & 91.691 & 88 & 348.52 & 5.87 & $8.00 \mathrm{E}+24$ & 0.29 & 35.39 & 14.63 \\
\hline $\begin{array}{l}\text { Imphal } \\
\text { (IMP) }\end{array}$ & 24.831 & 93.947 & 792 & 619.17 & 5.65 & $3.66 \mathrm{E}+24$ & 0.28 & 14.55 & 15.79 \\
\hline $\begin{array}{l}\text { Jorhat } \\
\text { (JOR) }\end{array}$ & 26.74 & 94.25 & 205 & 576.74 & 5.86 & $7.77 \mathrm{E}+24$ & 0.3 & 38.04 & 14.47 \\
\hline $\begin{array}{l}\text { Mokokchung } \\
\text { (MOK) }\end{array}$ & 26.321 & 94.526 & 1353 & 612.92 & 5.68 & $4.17 \mathrm{E}+24$ & 0.13 & 29.15 & 13.12 \\
\hline $\begin{array}{l}\text { Tadon } \\
\text { (TAD) }\end{array}$ & 27.31 & 88.602 & 1348 & 21.78 & 6.22 & $2.64 \mathrm{E}+25$ & 0.13 & 19.13 & 44.71 \\
\hline $\begin{array}{l}\text { Tura } \\
\text { (TRA) }\end{array}$ & 25.55 & 90.33 & 305 & 281.58 & 5.81 & $6.39 \mathrm{E}+24$ & 0.10 & 20.2 & 13.41 \\
\hline $\begin{array}{l}\text { Ziro } \\
\text { (ZIR) }\end{array}$ & 27.526 & 93.85 & 1600 & 529.42 & 5.65 & $3.72 \mathrm{E}+24$ & 0.26 & 31.47 & 13.73 \\
\hline
\end{tabular}

Table 2. Spectral parameters of $18^{\text {th }}$ September, 2011 Sikkim earthquake.

source time function. While calculating the Green's functions, the position of the epicentre are kept fixed. The inversion scheme uses a frequency band of 0.02 to 0.11. A fine grid search of the strike, dip and rake is performed for the best depth and moment. The final validation of the best fit solutions is accomplished by comparing the observed and synthetic seismograms. The $1 \mathrm{D}$ velocity model that is used may not be perfect and a small time shift is required for maximum correlation between the observed and synthetics [Marzooqi et al. 2008]. In the inversion technique, the shift is not known and it becomes a non-linear model parameter which has to be inverted along with the moment tensor and optimal source depth. To account for the horizontal mislocation, the synthetics are shifted relative to the observed by changing the origin time a few seconds before/after the origin time during the inversion. In this study, the inversion is carried out for full moment tensor. The preferred solution is obtained by a simple grid search over the focal depth with certain steps and also over the origin time between 1-2 sec. before/ after the location origin time, since the origin time trades off with focal depth. The solution that has a large percentage of variance and double couple component is selected.

There is no doubt that the usage of large station data with good azimuthal coverage yield a reliable focal mechanism solution. But in wave-form inversion technique, single station data or stations with less azimuthal coverage are sufficient to get an accurate solution. Several authors have undertaken comprehensive studies on the focal mechanism solutions derived from single or double station data e.g.: Rao [2009], Delouis and Legrand [1999], Fojtíkova and Zahradnik [2014], Zahradník et al. [2015] etc. In this study, we have used three components broad-band seismograms of nine stations e.g., TAD, DHU, TRA, GAU, ZIR, JOR, MOK, IMP, and DIB operated by IMD in the eight North-eastern states of India (Figure 2). The epicentral distances of the stations are $21.78 \mathrm{~km}, 219.38 \mathrm{~km}, 281.58 \mathrm{~km}$, $348.52 \mathrm{~km}, 529.42 \mathrm{~km}, 576.74 \mathrm{~km}, 612.92 \mathrm{~km}, 619.17 \mathrm{~km}$,

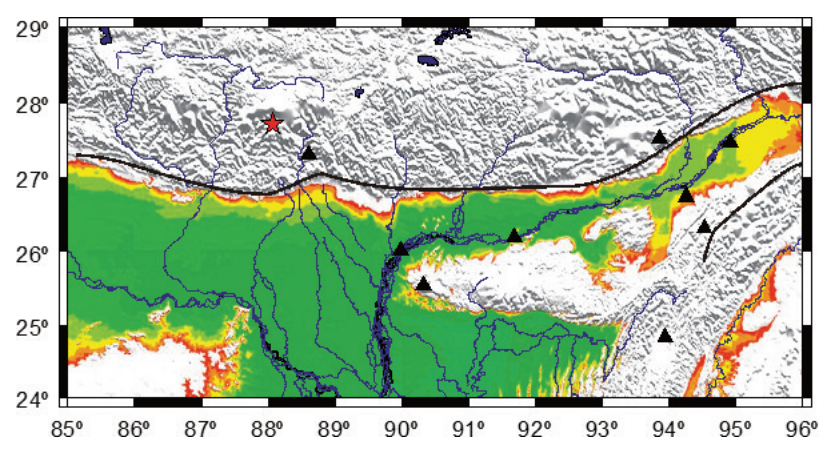

Figure 2. Distribution of seismic stations of IMD that were used in the waveform inversion of the 2011 Sikkim Himalaya earthquake (red star).

and $634.34 \mathrm{~km}$ respectively. The distances are compatible with the ISOLA software for local data (epicentral distances $\leq 1000 \mathrm{~km}$ ). A best waveform match between observed and synthetic seismograms of 18 th September, 2011 Sikkim earthquake are shown in Figure 3. Seismic moment $1.2 \mathrm{e}+026$ dyne-cm (Mw 6.7) is obtained through averaging the seismic moments from all the components of the recording stations. Finally a preferred 

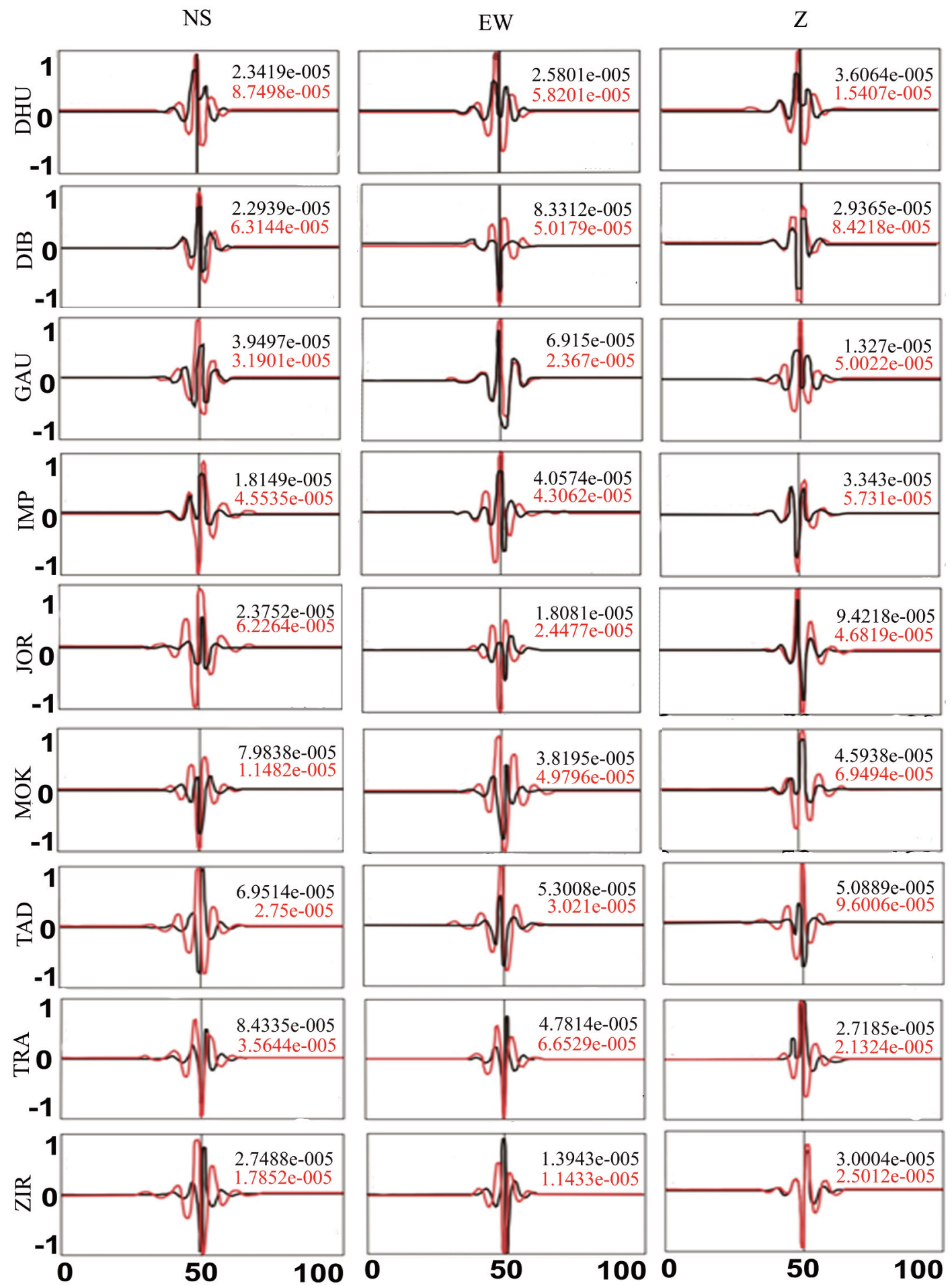

Figure 3. Matching of observed and synthetic seismograms for the Darjeeling-Sikkim Himalaya earthquake of $18^{\text {th }}$ September, 2011. The red colour indicates the synthetic and the black color indicates observed seismograms. Respective amplitudes are also shown on the left hand side of each station, along with the variance reduction between the waveforms on right hand side.

solution is obtained (red beach ball) based on maximum correlation between source position and time-shift (Figure 4). It can be seen that the preferred solution (red beach ball) differs from the nearby solutions in terms of DC percentage and correlation value (Figures 4, 5). As illustrated in Figures 4 and 5, it is ascertained from the correlation value that the preferred solution is well correlated at a depth of $47 \mathrm{~km}$ for a time-shift of $0.6 \mathrm{sec}$ having a DC\% of 90 . This result is in conformity with the results of GCMT data. Similarly, we have determined the focal mechanism solutions of the four aftershocks using the same technique. The final results are illustrated in Table 1.

In order to check the stability of our solutions we also applied the CAP waveform inversion technique [Zhu and Helmberger 1996, D’Amico et al. 2010]. Using 


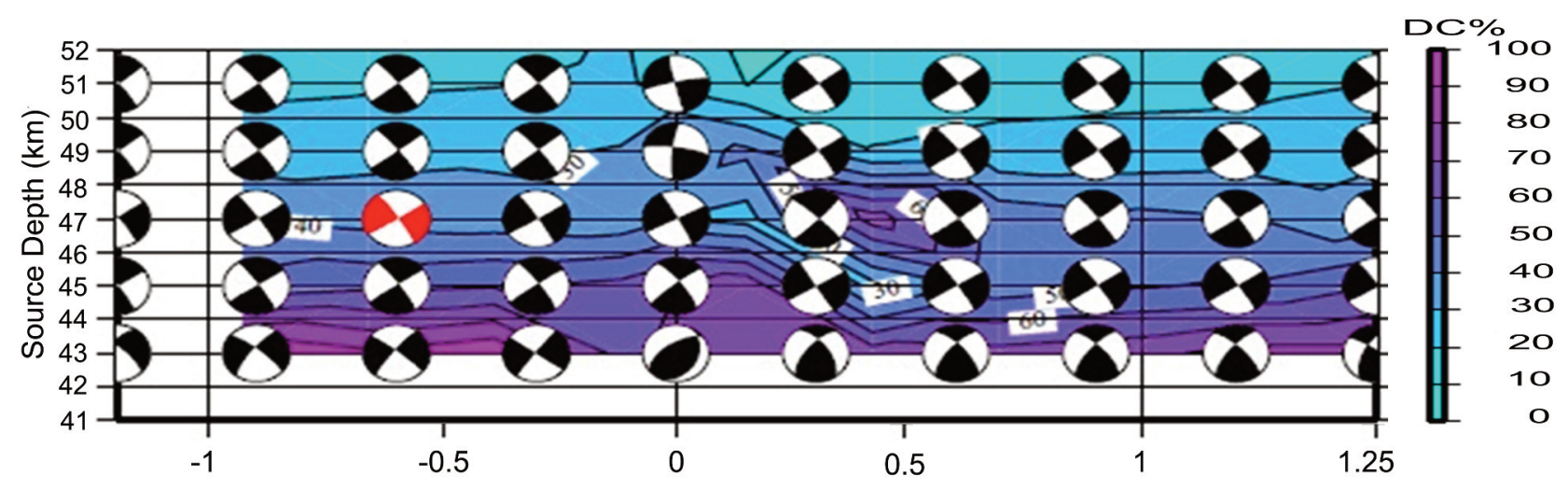

Figure 4. Plot of correlation vs time-shift, source depth and focal mechanism for the multiple source inversion for $18^{\text {th }}$ September, 2011 Darjeeling-Sikkim earthquake. The largest correlation was obtained for source depth $47 \mathrm{~km}$ and $0.6 \mathrm{sec}$ time shift. The preferred solution is depicted by a red beach ball.

this method, it is possible to separate the entire records into body waves and surface waves and model them separately avoiding influence by shallow crustal heterogeneities [D'Amico et al. 2010, 2011]. The CAP method minimizes the misfit between the observed and synthetic seismogram using a grid search to obtain the best moment magnitude, source depth and focal mechanism [Zhu and Helmberger 1996]. It has been proven to be a stable and reliable method for computing moment tensor solution for small and moderate events [D'Amico et al. 2010, 2011, 2012, 2013, 2014, 2016; D'Amico 2014, Orecchio et al. 2016]. In this case, uncertainties of focal mechanisms and depths were estimated by the methods and the statistical approaches described by Bevington and Robinson [2003]. In general, we found that the uncertainties associated with the focal mechanism solution parameters are in the order of a few degrees.

The spectral parameters are estimated by fitting every P-wave displacement spectrum with theoretical general model for displacement spectra as expressed by Equation (1). The waveform analysis tools in seismology

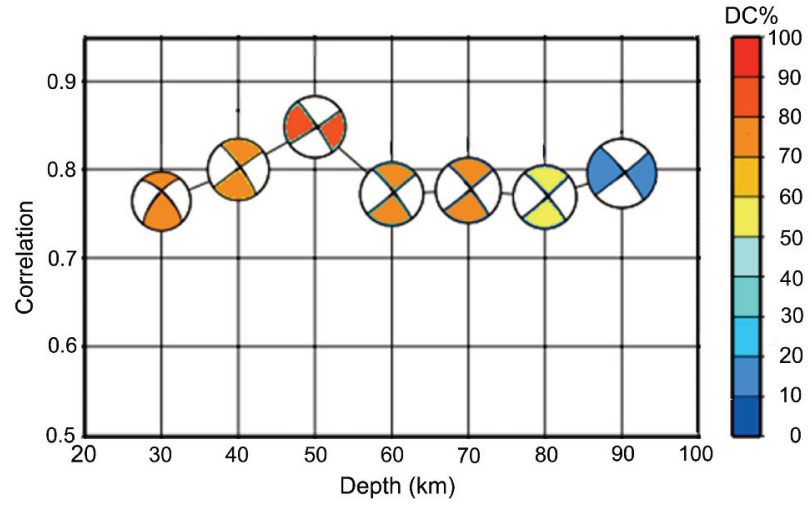

Figure 5. Correlation plot for the inversion results of $18^{\text {th }}$ September, 2011 Darjeeling-Sikkim earthquake. Scales for DC\% and correlation are shown on the right.

SeismoGRAPHer by Abdelwahed [2012] is used to estimate the spectral parameters. In this technique the Marquard Linearized Least-square method is used to solve the non-linear problem [Press et al. 1989]. The best fits of the observed displacement spectra to the theoretical one at a number of stations are plotted in Figure 6. The av-

\begin{tabular}{|c|c|c|c|c|c|}
\hline AFTERSHOCK & Mw & $\begin{array}{c}\text { Mo } \\
\text { (dyne.sec) }\end{array}$ & $\begin{array}{c}f c \\
(\mathrm{~Hz})\end{array}$ & $\begin{array}{c}\text { STRESS } \\
\text { DROP } \\
\text { (bars) }\end{array}$ & $\begin{array}{c}\text { SOURCE } \\
\text { RADIUS } \\
(\mathrm{km})\end{array}$ \\
\hline 1 & 4.51 & $8.77 \mathrm{E}+22$ & 0.37 & 11.31 & 4.43 \\
\hline 2 & 4.35 & $4.78 \mathrm{E}+22$ & 0.37 & 10.47 & 3.96 \\
\hline 3 & 4.86 & $3.62 \mathrm{E}+23$ & 0.26 & 17.95 & 10.49 \\
\hline 4 & 3.9 & $8.87 \mathrm{E}+21$ & 0.21 & 20.2 & 2.68 \\
\hline
\end{tabular}

Table 3. Average Source parameter values of the aftershocks of $18^{\text {th }}$ September, 2011 Sikkim earthquake. 

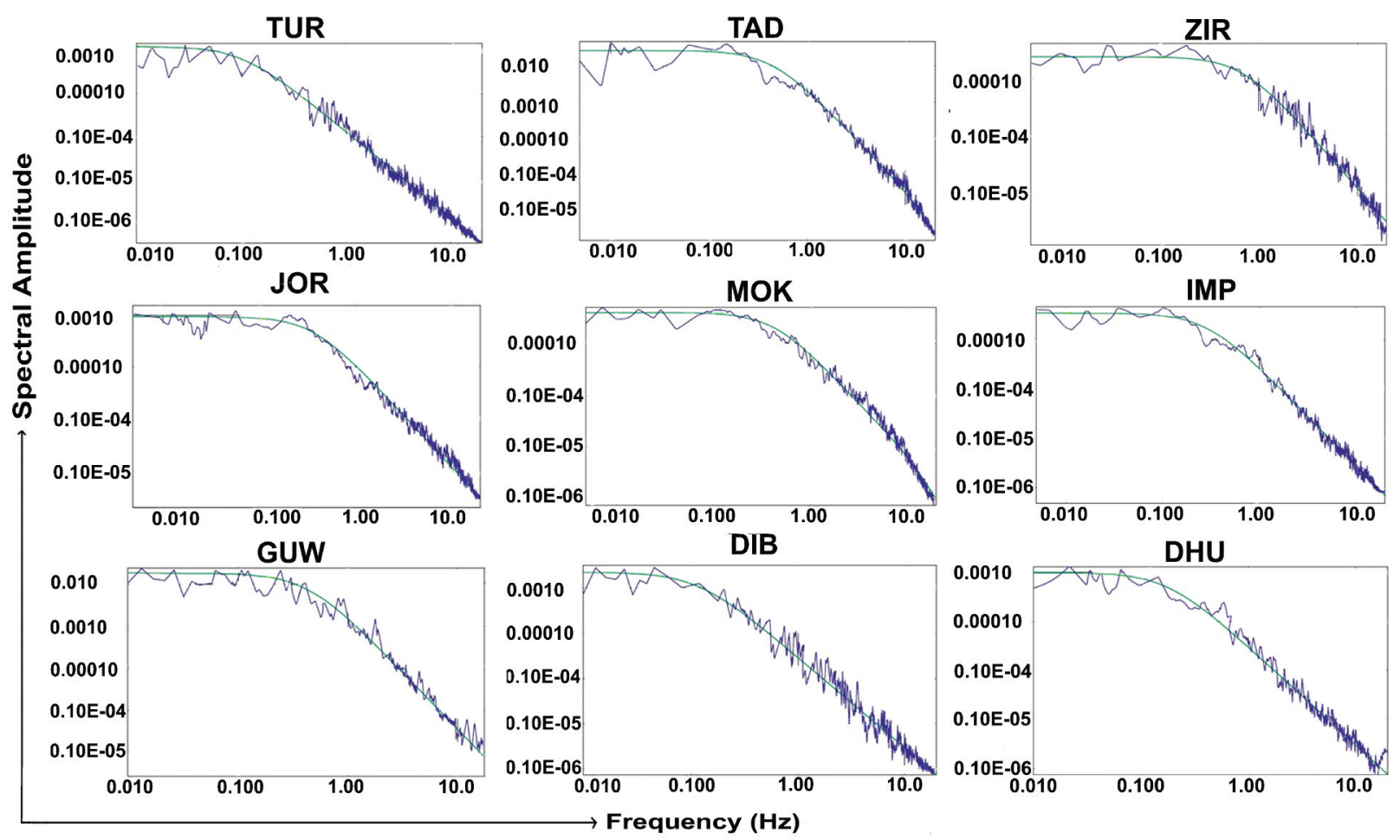

Figure 6. Observed spectrum for different stations using Brune (1970) model for the 2011 Sikkim earthquake of Mw 6.9.

erage value of corner frequency, stress drop and source radius are $0.19 \mathrm{~Hz}, 25.65$ bars, $16.94 \mathrm{~km}$, respectively. From our calculation it is seen that for stations with epicentral distance $>200 \mathrm{~km}$, the value of Mw estimated from spectral analysis is lower than the Mw value estimated from waveform inversion. This discrepancy may be due to the attenuation factor considered in the calculation of spectral parameters. It is noted that Chopra et al. [2013] estimated the spectral parameters 2011 Sikkim earthquake by using different accelerograph records. The reported values of corner frequency, seismic moment, stress drop and source radius were $0.12 \mathrm{~Hz}, 115$ bars, $9.68 \mathrm{~km}$, respectively, which are consistent with our results, except the stress-drop value. In addition to these, we have estimated the spectral parameters of all the four aftershocks which also show low value of stress-drop (Table 3).

\section{Discussion and Conclusions}

The most widely accepted tectonic model to understand the Himalayan large earthquakes has been the steady state tectonic model envisaged by Seeber et al. [1981] and Ni and Barazangi [1984]. This model suggested that in the Himalayan Seismic Belt (HSB), earthquakes between the MBT and MCT are confined above the plane of detachment. However, several authors [e.g. Mukhopadhyay and Dasgupta 1988, De and Kayal 2003, Baruah et al. 2014] have reported that in the plane of detachment, shallow thrust faulting earthquakes as envisaged in the HSB tectonic model, are not evident in the Sikkim Himalaya and its foot-hills region. The Moho in the Sikkim Himalaya has been interpreted by de la Torre et al. [2007] to lie at 40-80 km depth. The earthquakes at 20-40 km depth between Main Himalayan Thrust and the Moho contain several strikeslip earthquakes [de la Torre et al. 2007], which suggest the presence of strike-slip faults in the region that extend below MHT or the basal decollement (basal detachment) of the Sikkim Himalayan wedge. Mukul et al. [2014] suggested that both MHT and Lesser Himalayan Duplex (LHD) as active structures in Sikkim Himalaya. They emphasized that the DarjeelingSikkim area, may be releasing accumulated strain through frequent moderate and micro earthquakes and the seismicity in general appears to be located between MCT and MBT. Furthermore, they suggest shortening in the area accommodated along active east-west trending faults in LHD in Tista Half Window (THW). This view is supported by the presence of a thrust component in the focal mechanism solution of one of the aftershocks of 2011 Sikkim earthquake. The mainshock with dextral strike-slip movement may be related with the incessant Duplex activity of the weaker well foliated meta-sedimentary rock sequences of the region, combined with the active convergence of Indian and Eurasian plates.

In the present study, a plan and sectional view of a part of the Darjeeling-Sikkim-Tibet Himalayan wedge [modified after Mottram et al. 2011, Mukul et al. 2014] shows the indicative dextral strike-slip movement (Fig- 


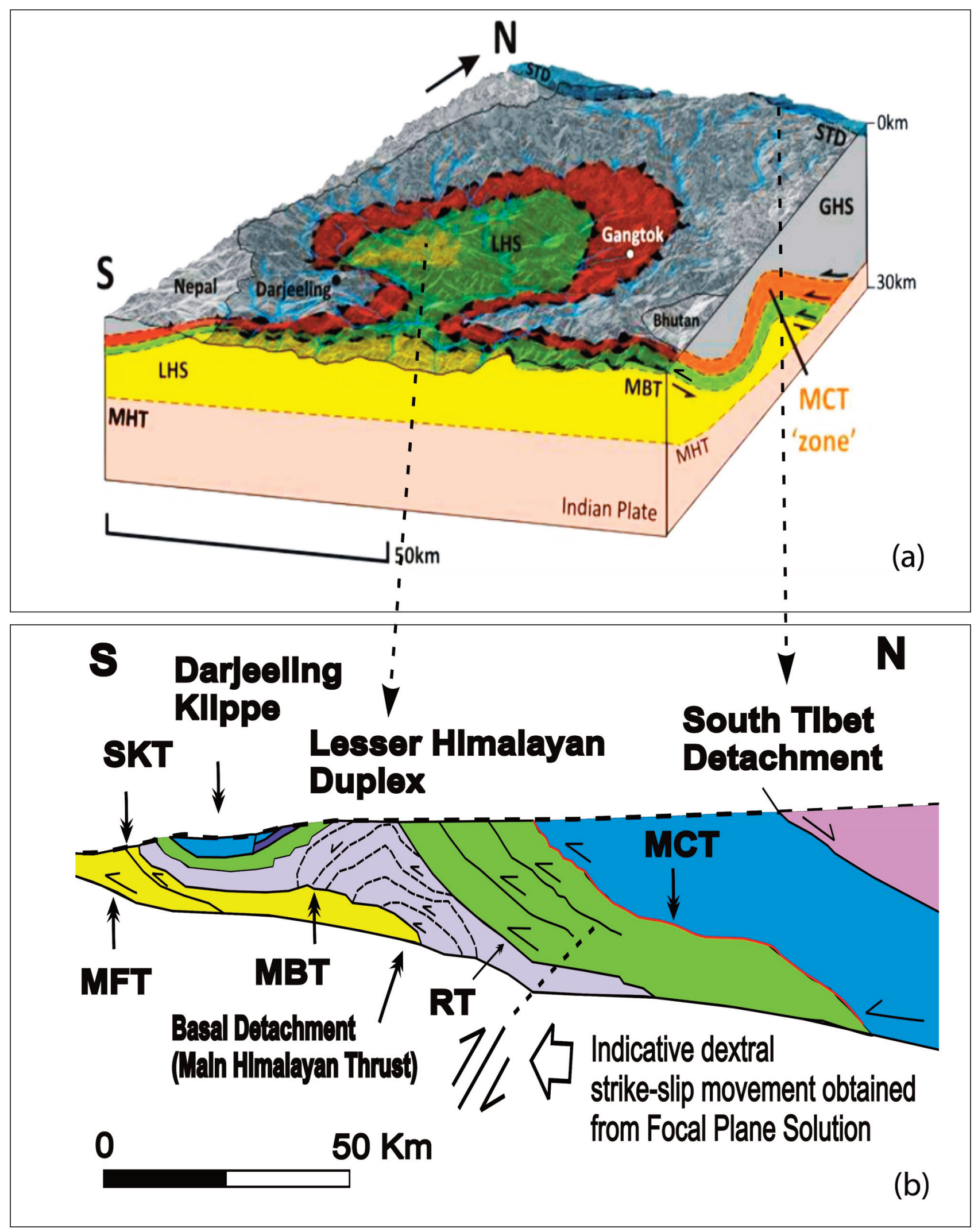

Figure 7. (a) 3D cross-section view (after Mottram et al. 2011) \& (b) Sectional view of a part of the Darjiling-Sikkim-Tibet Himalayan wedge with the Lesser Himalayan Duplex (LHD) (modified after Mukul et al. 2014) along with the tentative strike slip motion underneath the basal detachment is shown. SKT: South Kalijhora Thrust; MCT: Main Central Thrust; RT: Ramgarh Thrust; MBT: Main Boundary Thrust; MFT: Main Frontal Thrust; STD: South Tibet Detachment; LHS: Lesser Himalayan Series; GHS: Greater Himalayan Series.

ure 7) beneath the MHT which might have occurred due to relative motion between converging plates resulting in stress accumulation within the plates as well as along their common boundary [e.g. Mukul et al. 2010]. 
The GCMT solution of the 2011 Sikkim earthquake in the eastern Himalaya shows that it occurred at greater depth $(\sim 47 \mathrm{~km})$ by strike-slip mechanism (Figure 1). A similar strike slip solution is obtained in this study using local broadband network data with an estimated depth of $47 \mathrm{~km}$ (Figure 1). We have also examined fault plane solutions of the four significant aftershocks (Mw 3.9- 4.5) using the local network data. The waveform inversion results show that three aftershocks occurred by strike-slip mechanisms and one by thrust faulting with strike slip component. Additionally, fault plane solutions of the past two medium to strong earthquakes (1965 and 1980) in main shock epicenter area also show dominantly strike slip solutions (Figure 1). In all these solutions of the 2011 main shock, aftershocks and the past events (1965 and 1980), the NNW-SSE striking nodal plane is comparable with the Tista fault.

The agreement between the different solutions has also been numerically checked by applying the Kagan [1991] method [D’Amico et al. 2011 and reference therein]. The Kagan angle measures the rotation that should be applied to one earthquake source doublecouple to make it coincident with another one. The agreement is very good between being in the order of $85-90 \%$. The small differences among the solutions can be attributed to a combination of several factors for example the use of different velocity model, or different frequency bands. However, we are confident that the final focal mechanisms obtained in this study are robustly determined.

The geologically mapped Tista lineament (GSI 2000) was reported as Tista fault by Kayal et al. [2011] and Baruah et al. [2014]. It may also be noted that the 1988 strong earthquake (Mw 6.9) in the foot-hills region also shows strike slip mechanism with an estimated depth 55-60 km (Figure 1) [Banghar 1991]. A NW-SE transverse fault, termed the West Patna fault, was inferred to be the causative fault for this strike slip earthquake (GSI 2000).

The source parameters that are estimated from the displacement spectra of the broadband seismograms show that the stress drop of the main shock and aftershock sequence has a low value, ranging from 14-38 bars. Similar observation is reported in geodetic measurements by Pradhan et al. [2013]. They have inferred an average coseismic displacement of $\sim 11 \mathrm{~mm}$ at Phodong and $\sim 9 \mathrm{~mm}$ at Taplejung station near the main shock epicentre. It is important to note that low stress drop in other parts of the world are interpreted as the result of re-rupturing after short healing times [Kanamori et al. 1993, Berberian et al. 1999]. Here, this argument, however, may not hold true because no large earthquake is reported in the Sikkim Himalaya during the recorded history except two medium magnitude earthquakes, one in 1965 (mb 5.8) and the other in 1980 ( $\mathrm{mb}$ 6.0) respectively. The eastern Himalayan seismicity differs from that of the western Himalaya. The western Himalayan earthquakes are shallow and occur by thrust mechanisms, whereas the Sikkim Himalayan or eastern Himalayan earthquakes are deeper and occur by strike slip mechanisms. Several authors [e.g. Mukhopadhyay 1984, Engdhal et al. 1998, Kayal 2001 and 2010, De and Kayal 2003, Monsalve et al. 2006 and Baruah et al. 2014] reported that the earthquakes occur in the upper half of the crust but much activity is also observed in the lower crust and at the crust-mantle boundary beneath Sikkim and western Nepal. The aftershocks recorded by the local microearthquake network in the Sikkim Himalaya show a vertical structure down to $50 \mathrm{~km}$ depth [Ravi Kumar et al. 2012]. This structure is comparable with the Tista fault, which is a mantle reaching vertical fault [Kayal et al. 2011, Baruah et al. 2014]. The 2011 main shock occurred on this vertical structure by strike slip mechanism in a lower friction condition than those shallow thrust faulting Himalayan earthquakes on the plane of detachment in the western Himalaya. In the eastern Himalaya, the long NE and NW trending transverse structures/faults from foredeep to the high Himalaya, or even beyond (Figure 1), may predate the birth of the Himalaya, producing intersecting patterns, and accommodating the plate convergence by conjugate shear failure on some of these faults [e.g. Mukhopadhyay 1984, Dasgupta et al. 1987, Kayal et al. 2011]. Such shear failures may be explained by oblique transverse faulting to the direction of regional compression as it is happening in the eastern Himalaya. The mantle reaching Tista fault that existed before the two plates came into collision, reactivated in contrast to the thrust kind of slip of Himalayan seismic belt; this may cause lower stress drop. Presence of transverse structures in different parts of the Himalayan arc, including the Sikkim Himalaya, indicates that the deformation in the long arc is not at all continuous [e.g. Pandey et al. 1999]. Receiver function estimates to the Moho shows that the entire crust beneath the Sikkim Himalaya is seismogenic and the seismicity is diffused in nature [Acton et al. 2011]. The diffused seismicity may be due to the presence of more than one seismogenic fault in the Main Himalayan Thrust system, either out-of-sequence and or reactivated faults [Mukul et al. 2014]. While the GPS study indicates that the rate of convergence in the Sikkim Himalaya and the western part of Bhutan is about $12 \mathrm{~mm} /$ year, out of which $5 \mathrm{~mm} /$ year of aseismic slip 
is being accommodating at the north of the Tista lineament [Mukul et al. 2014]. Moreover, the variable bvalue in the range of (0.74-1.18) in the Sikkim Himalaya region suggests heterogeneities in the lithosphere [Mishra et al. 2010], which in turn probably makes it favourable for low-friction conditions. Earthquakes due to deep-rooted transverse tectonics in the study region seem to indicate new trends to be followed for the plate tectonics study of India-Eurasia plate conversion.

Acknowledgements. We thank Dr. D. Ramaiah FNASc, FNA, Director, CSIR-North East Institute of Science and Technology (CSIR-NEIST), Jorhat, for his kind support and encouragement in carrying out this work. We thank Prof. Harsh K. Gupta, Former Chairman, Research Council, CSIR-NEIST-J, Prof. J. R. Kayal, Former Deputy Director General (Geophysics), Geol Surv India and Dr. Saurabh Baruah, Head, GSTD, CSIR-NEIST for their encouragement. We also thank Dr. Belinda Gambin, University of Malta, Malta for her valuable help in preparing this manuscript. Special thanks to the Editors and the Reviewers for their constructive comments. The Science \& Engineering Research Board (SERB), Government of India provided the financial support under Young Scientist Scheme, vide Sanction No. SR/FTP/ES-121/2014.

\section{References}

Abdelwahed, M.F., 2012. SGRAPH (SeismoGRAPHer): Seismic waveform analysis and integrated tools in seismology. Comput. Geosci. 40, 153-165.

Acton, C.E., Priestley, K., Mitra, S. and Gaur, V.K., 2011. Crustal structure of the Darjeeling-Sikkim Himalaya and southern Tibet. Geophysical Journal International, 184(2), pp.829-852.

Allegre, C.J., Courtillot, V., Tapponnier, P., Hirn, A., Mattauer, M., Coulon, C., Jaeger, JJ., Achache, J., Sch€arer, U., Marcoux. J., et al. 1984. Structure and evolution of the Himalaya-Tibet orogenic belt. Nature 307, 17-22.

Archuleta, R.J., Cranswick, E.C., Muller, C., Spudich, P., 1982. Source parameters of the 1980 Mammoth Lakes, California, earthquakes sequence. J. Geophys. Res. 87, 4595-4607.

Baccheschi P., D’Amico S., 2014. Subduction, volcanism, collision, orogenesis and faults: How do they shape the central Mediterranean region? Journal of Geodynamics. 82, 1-4, doi: http: / / dx.doi.org/10.1016/j.jog.2014.09.010.

Banghar, A.R., 1991. Mechanism solution of NepalBihar earthquake of August 20, 1988. J. Geol. Soc. India 37:25-30.

Baruah, S., Baruah, S., Bora, P., Duarah, R., Kalita, A., Biswas, R., Gogoi, N., Kayal, J.R., 2012a. Moment magnitude (MW) and local magnitude (ML) rela- tionship for earthquakes in northeast India. Pure Appl. Geophys. 169:1977-1988.

Baruah, S., Baruah, S., Kalita, A., Biswas, R., Gogoi, N., Gautam, J.L., Sanoujam, M., Kayal, J.R., 2012b. Moment magnitude - local magnitude relationship for the earthquakes of the Shillong-Mikir plateau, northeastern India region: a new perspective. Geomatics Nat. Haz. Risk. 3:365-375.

Baruah, S., Saikia, S., Baruah, S., Bora, P.K., Tatevossian, R., Kayal, J.R., 2014. The September 2011 Sikkim Himalaya earthquake Mw 6.9: is it a plane of detachment earthquake? Geomatics Nat. Haz. Risk, http: / / dx.doi.org/10.1080/19475705.2014.895963.

Berberian, M., Yeats, R.S., 1999. Patterns of historical earthquake rupture in the Iranian Plateau. Bull. Seismol. Soc. Am. 89, 1, 120-139.

Bevington, P.R. and Robinson, D.K., 2003. Data Reduction and Error Analises. 3-d edition.

Boore, D.M., Boatwright, J., 1984. Average body-wave radiation coefficients. Bull. Seismol. Soc. Am. 74, 1615-1621.

Bouchon, M., 1981. A simple method to calculate Green's functions for elastic layered media. Bull. Seismol. Soc. Am. 71, 959-971.

Brune, J. N., 1970. Tectonic stress and the spectra of seismic shear waves from earthquakes. J. Geophys. Res. 75, 4997-5009.

Chopra, S., Sharma, J., Sutar, A., Bansal, B.K., 2013. Estimation of Source Parameters of Mw 6.9 Sikkim Earthquake and Modeling of Ground Motions to Determine Causative Fault. Pure Appl. Geophys. 170, 12, 2127-2138.

D’Amico S., Orecchio B., Presti D., Zhu L., Herrmann R. B., Neri G., 2010. Broadband waveform inversion of moderate earthquakes in the Messina straits, Southern Italy, Physics of Earth and Planetary Interiors, 179, 97-106, doi: 10.1016/j.pepi.2010.01.012

D’Amico S., Orecchio B., Presti D., Gervasi A., Guerra I., Neri G., Zhu L., Herrmann R. B., 2011. Testing the stability of moment tensor solutions for small and moderate earthquakes in the Calabrian-Peloritan arc region. Boll. Geo. Teor. Appl., 52, 283-298 doi:10.4430/bgta0009

D’Amico S., Gervasi A., Guerra I., Neri G., Orecchio B., Presti D., Totaro C., 2012. Seismicity and Focal Mechanisms at the Calabro-Lucanian boundary along the Apennine chain (southern Italy), Rend. Online Soc. Geol. It., Vol. 21, 778-779

D’Amico S., Orecchio B., Presti D., Neri G., Wu W.-N., Sandu I., Zhu L., Herrmann R. B., 2013. Source parameters of small and moderate earthquakes in the area of the 2009 L'Aquila seismic sequence (central 
Italy). Physics and Chemistry of the Earth, 63, 7791, doi:10.1016/j.pce.2013.02.005

D’Amico S., 2014. Source parameters related to a small earthquake swarm off-shore of Malta (central Mediterranean). Development in Earth Science, 2, 8-13

D’Amico S., Cammarata L., Cangemi M., Cavallaro D., Di Martino R., Firetto Carlino M., 2014. Seismic moment tensors and regional stress in the area of the December2013-January 2014, Matese earthquake sequence (Central Italy). Journal of Geodynamics, 82, 118-124, doi: http: / / dx.doi.org/10.1016/j.jog.2014.09.008

D’Amico S., Evangelidis C., Sokos E., 2016. Studying seismic sources: Theory, methods and applications, Physics and Chemistry of the Earth, DOI:10.1016/j.pce.2016.10.009.

De la Torre, T. L., Monsalve, G., Sheehan, A. F., Sapkota, S. and Wu, F., Earthquake processes of the Himalayan collis ion zone in eastern Nepal and the southern Tibetan Plateau. Geophys. J. Int., 2007, 171, 718-738.

Dasgupta, S., Mukhopadhyay, M., Nandy, D.R., 1987. Active transverse features in the central portion of the Himalaya. Tectonophysics 136:255-264.

Dasgupta, S., Mukhopadhyay, B., Mukhopadhyay, M., Nandy, D.R., 2013. Role of transverse tectonics in the Himalayan collision: further evidences from two contemporary earthquakes. J. Geol. Soc. India. 81:241-247.

De R., Kayal, J.R., 2003. Seismotectonic model of the Sikkim Himalaya: constraint from microearthquake surveys. Bull. Seismol. Soc. Am. 93:1395-1400.

Delouis, B. and D. Legrand, 1999. Focal mechanism determination and identification of the fault plane of earthquakes using only one or two near-source seismic recordings. Seismological Society of America Bulletin, 89, 1558-1574.

Engdahl, E.R, van der Hillst, R., Buland, R.P., 1998. Global teleseismic earthquake relocation with improved travel times and procedures for depth determination. Bull. Seismol. Soc. Am. 88:3295-3314.

Fojtíkova, L., Zahradnik, J., 2014. A new Strategy for weak events in Sparse networks: the first-motion polarity solutions constrained by single-station wave-form inversion. Seismol. Res. Lett. 85 (6), 1265 e 1274. http:/ / dx.doi.org/10.1785/ 0220140072.

GSI, 2000. Seismotectonic Atlas of India and Its Environs. Geological Survey of India Publication.

Hanks, T.C., Wyss, M., 1972. The use of body wave spectra in the determination of seismic-source parameters. Bull. Seismol. Soc. Am. 62, 561-589.
Hanks, T.C., Kanamori, H., 1979. A moment magnitude scale. J. Geophys. Res. 84, 2348-2350.

INTACH, 2012. Earthquake damage assessment vulnerability of Sikkim's built heritage, Indian National Trust for Art and Cultural Heritage, New Delhi. Available from: http: / www.intach.org/

Joshi, A., Kumari, P., Singh, S., Sharma, M.L., 2012. Near-field and far-field simulation of accelerograms of Sikkim earthquake of September 18, 2011 using modified semi-empirical approach. Nat Hazards 64:1029-1054.

Kagan, Y.Y., 1991. 3-D rotation of double-couple earthquake sources. Geophysical Journal International, 106(3), pp.709-716.

Kanamori, H., Mori, J., Hauksson, E., Heaton, T.H., Hutton, L.K.., Jones, L.M., 1993. Determination of earthquake energy release and ML using TERRAscope. Bull. Seismol. Soc. Am. 83, 2, 330-346.

Keilis-Borok, V.I., 1959. On the estimation of the displacement in the earthquake source and source dimensions. Anna Geofis. 12, 205-214.

Kayal, J.R., 2001. Microearthquake activity in some parts of the Himalaya and the tectonic model. Tectonophysics 339:331-351.

Kayal, J.R., 2010. Himalayan tectonic model and the great earthquakes: an appraisal. Geomatics Nat Hazards Risk 1:51-67.

Kayal, J.R., Srivastava, V.K., Kumar, P., Chatterjee, R., Khan, P.K., 2011. Evaluation of crustal and upper mantle structures using receiver function analysis: ISM broadband observatory data. J. Geol. Soc. India 78, 1, 76-80.

Lienert, B.R., Berg, B.E. and Frazer, L.N., 1986 Hypocenter: An earthquake location method using centered, scaled and adaptively damped least squares. Bull. Seismol. Soc. Am., 76, 771-783.

Mahajan, A.K., Gupta, V., Thakur, V.C., 2012. Macroseismic field observations of 18 September 2011 Sikkim earthquake. Nat. Hazards 63:589-603.

Marzooqi, Y. Al, Elenean, K.A., Megahed, A.S., El-Hussain, I., Rodgers, A.J. and Al Khatibi, E., 2008. Source parameters of March 10 and September 13, 2007, United Arab Emirates earthquakes. Tectonophysics, 460(1), pp.237-247.

Mishra, O.P., Chakrabortty, G. K., Singh, O. P., Ghosh, D. C., Mukherjee, K. K., and Das, P. C., 2010. A report on seismogenesis in the Sikkim-darjiling Himalayas and assimilation of dynamic snap shots of the region: future vulnerability, GSI Report (FSP: SEI/CHQ/CGD/2007/070), p. 57.

Monsalve, G., Sheehan, A.F., Pandey, M.R., Rajanre, S., Wu, F., 2006. Seismicity and 1-D velocity structure 
of the Himalayan collision zone: results from the Himalayan Nepal Tibet Seismic Experiment (HIMNT). J. Geophys. Res. 111:B10301, doi: 10.1029/2005JB004062

Mottram, C.M., Harris, N. B. W., Parrish, R. R., Argles, T. W., and Warren, C. J., Gupta, S., 2011. Shedding light on the Main Central Thrust Controversy, Sikkim Himalaya. 26th Himalaya-Karakoram-Tibet Workshop, Canmore, Canada, July 12-13, 2011; Journal of Himalayan Earth Sciences 44(1) 2011, 60-61.

Mukhopadhyay, M., 1984. Seismotectonics of transverse lineaments in the eastern Himalaya and its foredeep. Tectonophysics 109:227-240.

Mukhopadhyay, M., Dasgupta, S., 1988. Deep structure and tectonics of the Burmese arc: constraints from earthquake and gravity data. Tectonophysics 149 , 299-322.

Mukul, M., Jade, S., Bhattacharyya, A.K. and Bhusan, K. (2010) Crustal Shortening in Convergent Orogens: Insights from Global Positioning System (GPS) Measurements in Northeast India. JOUR.GEOL.SOC.INDIA, VOL.75, 302-312.

Mukul, M., Jade, S., Ansari,K. and Matin, A.(2014) Seismotectonic implications of strike-slip earthquakes in the Darjiling-Sikkim Himalaya. Current Science, Vol. 106, No. 2, 198-210.

Ni, J., Barazangi, M., 1984. Seismotectonics of the Himalayan collision zone: geometry of the underthrusting Indian plate beneath the Himalaya. J. Geophys. Res. 89:1147-1163.

Orecchio, B., Presti, D., Totaro, C., D’Amico, S., Neri, G., 2016. Seismological analyses in the Calabrian Arc region (southern Italy): Investigating the northern edge of the Ionian slab, Journal of Geodynamics, 88, 23-25, doi:10.2016/j.jog.2015.04.003.

Pandey, M.R., Tandukar, R.P., Avouac, J.P., Vergne, J. and Heritier, T., 1999. Seismotectonics of the Nepal Himalaya from a local seismic network. Journal of Asian Earth Sciences, 17(5), pp.703-712.

Paul, H., Mitra, S., Bhattacharya, S.N. and Suresh, G., 2015. Active transverse faulting within underthrust Indian crust beneath the Sikkim Himalaya. Geophysical Journal International, 201(2), pp.1072-1083.

Pradhan, R., Prajapati, S., Chopra, S., Kumar, A., Bansal, B.K., Reddy, C.D., 2013. Causative source of Mw 6.9 Sikkim-Nepal border earthquake of September 2011: GPS baseline observations and strain analysis. J. Asian Earth Sci. 70-71:179-192.

Press, H.W., Flannerry, P.B., Teukolsky, A.S., Vetterling, T.W., 1989. Numerical Recipes. The Art of Scientific Computation (Fortran Version), Cambridge University Press, Europe.
Raghukanth, S.T.G., Lakshmi Kumari, K. and Kavitha, B., 2012. Estimation of ground motion during the 18th September 2011 Sikkim Earthquake. Geomatics, Natural Hazards and Risk, 3(1), pp.9-34.

Rai, D.C., Singhal, V., Mondal, G., Parool, N., Pradhan, T., Mitra, K., 2012. The M 6.9 Sikkim (India-Nepal Border) earthquake of 18 September 2011. Curr. Sci. 102:1437-1446.

Rao, N. P. 2009. Single station moment tensor inversion for focal mechanisms of Indian intra-plate earthquakes, Current Science, 77( 9), 1184-1188.

Rajendran, K., Rajendran, C.P., Thulasiraman, N., Andrews, R., Sherpa, N., 2011. The 18 September 2011, north Sikkim earthquake. Curr. Sci. 101:1475-479.

Ravi Kumar, M., Hazarika, P., Prasad, G.S., Singh, A., Saha, S., 2012. Tectonic implications of the September 2011 Sikkim earthquake and its aftershocks. Curr. Sci. 102:788-792.

Seeber, L., Armbruster, J.G., Quittmeyer, R., 1981. Seismicity and continental subduction in the Himalayan Arc. In: Gupta HK, Delany FM, editors. Zagros, Hindu Kush, Himalaya, geodynamic evolution, geodynamics series. Washington (DC): American Geophysical Union; p. 215-242.

Sharma, M.L., Sinvhal, A., Singh, Y., Maheshwari, B.K., 2013. Damage survey report for Sikkim earthquake of 18 September 2011. Seismol. Res. Lett. 84:49-56.

Sokos, E.N. and Zahradnik, J., 2008. ISOLA a Fortran code and a Matlab GUI to perform multiple-point source inversion of seismic data. Computers $\&$ Geosciences, 34(8), pp.967-977.

Thakur, V.C., Mahajan, A.K., Gupta, V., 2012. Seismotectonics of 18 September 2011 Sikkim earthquake: a component of transcurrent deformation in eastern Himalaya. Himalayan. Geol. 33:89-96.

Thirunavukarasu, A., Kumar, A. and Mitra, S., 2016. Lateral variation of seismic attenuation in Sikkim Himalaya. Geophysical Supplements to the Monthly Notices of the Royal Astronomical Society, 208(1), pp.257-268.

Zahradník, J., Fojtíkova, L., Carvalho, J., Barros, L.V., Sokos, E., Janský, J., 2015. Compromising polarity and waveform constraints in focal-mechanismsolutions; the Mara Rosa 2010 Mw 4 central Brazil earthquake revisited, Journal of South American Earth Sciences, 63, 323-333, http: / / dx.doi.org/10.1016/j.jsames.2015.08.011.

Zhu, L. and Helmberger, D.V., 1996. Advancement in source estimation techniques using broadband regional seismograms. Bulletin of the Seismological Society of America, 86(5), pp.1634-1641. 
*Corresponding author: Santanu Baruah,

Geosciences \& Technology Division, CSIR-North East Institute of Science $\&$ Technology (NEIST), Jorhat-6, Assam, India; email: santanub27@gmail.com.

C 2018 by the Istituto Nazionale di Geofisica e Vulcanologia. All rights reserved. 
BARUAH ET AL. 
STUDY OF FAULT PLANE SOLUTIONS OF 2011 SIKKIM EARTHQUAKE 
BARUAH ET AL. 
STUDY OF FAULT PLANE SOLUTIONS OF 2011 SIKKIM EARTHQUAKE 
BARUAH ET AL.

20 
STUDY OF FAULT PLANE SOLUTIONS OF 2011 SIKKIM EARTHQUAKE 
BARUAH ET AL. 